\title{
Interferon Gamma Release Assay and Tuberculin Skin Test in the Diagnosis of Latent Tuberculosis among Health Care Workers - A Comparative Study
}

\author{
Reshmi Gopalakrishnan ${ }^{*}$ and G.S. Vijay Kumar ${ }^{2}$ \\ ${ }^{1}$ Department of Microbiology, Malabar Medical College Hospital and \\ Research Centre, Calicut, Kerala, India \\ ${ }^{2}$ Kodagu Institute of Medical Science, Madikeri, Karnataka, India \\ *Corresponding author
}

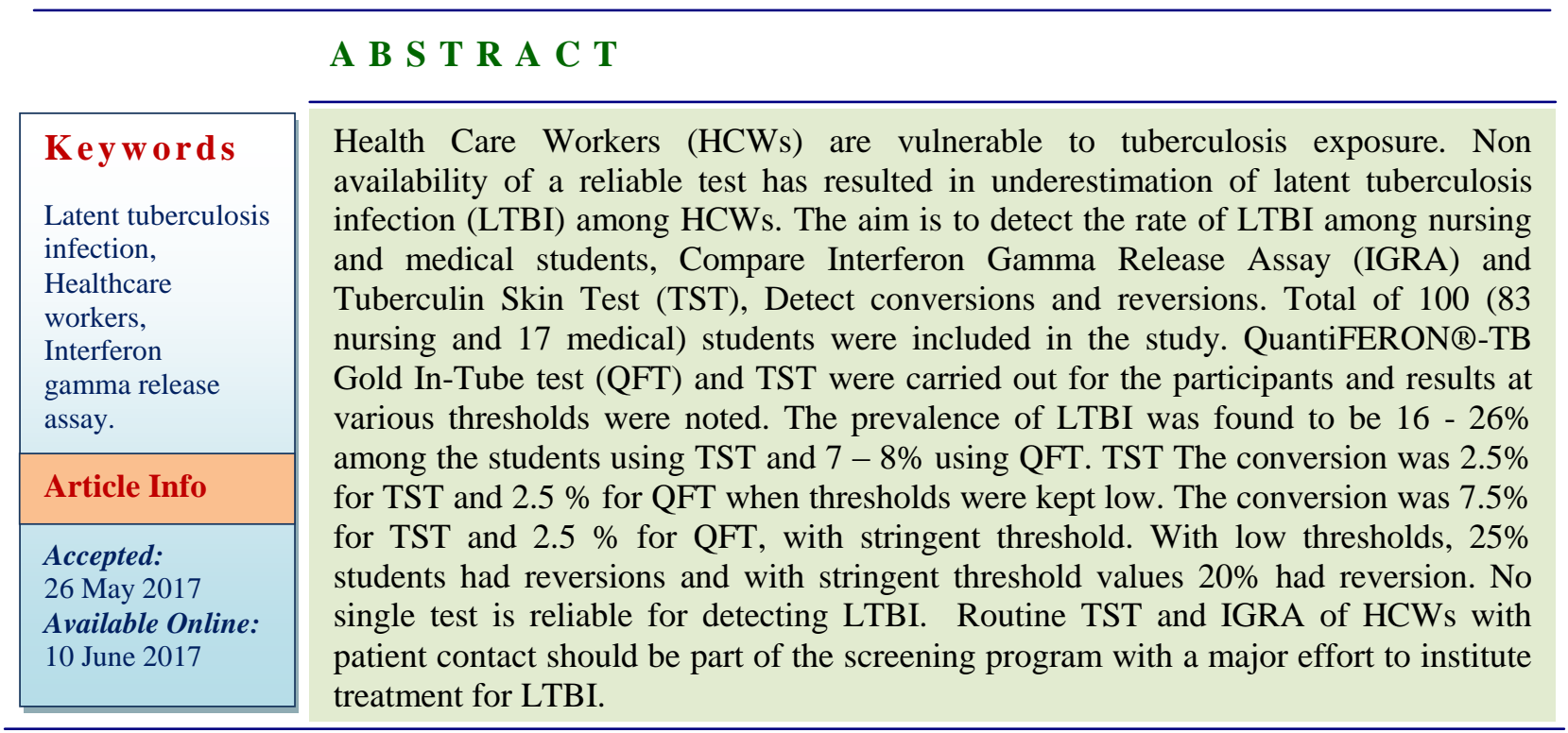

\section{Introduction}

Tuberculosis (TB) infects an estimated of one-third of the world's population, and about 9 million cases occur every year. $90 \%$ of the infected people develop LTBI. Though the individuals are not infectious, they risk progression to active $\mathrm{TB}$ at a later stage (Mack et al., 2009). About 3 to 5\% of Latent tuberculosis (LTB) develops into active TB in first year and about 5 to $15 \%$ later.

People with LTBI can serve as potential reservoirs for future acute infections if the host immune system is compromised. A person with LTBI progressing to active TB can be reduced by $90 \%$ with proper treatment. Screening of HCWs for TB is an important component of infection control program. The risk of transmission of $M$. tuberculosis from patients to HCWs is a neglected problem in many low and middle-income countries (Joshi et al., 2006). LTBI is difficult to diagnose because MTB is difficult to detect by smear study and needs alternative methods like TST and the latest method of Interferon Gamma Release Assays (IGRAs). 


\section{Materials and Methods}

A descriptive study was conducted in a tertiary care hospital. A total of 100 health care students participated in the study. A written consent was taken from all the participants. The participants included 83 first year nursing students and 17 second year medical students. Average age of the subjects ranged from 17 to 19 years. Students with past history of active tuberculosis, those receiving anti tuberculosis medications were excluded from the study. Clinical history, physical examination findings, BCG scar appearance were recorded for each participant. Data such as exposure with an index case was also recorded.

Blood required for the QFT assay were drawn in the QFT tubes. TST was performed by using the Mantoux technique, by injecting $0.1 \mathrm{ml}$ of $5 \mathrm{TU}$ of PPD on the volar aspect of forearm. TST results were read after 48 hours. The transverse diameter of the in duration was recorded in millimetres after 48 hours. A cutoff of $\geq 15 \mathrm{~mm}$ in duration was considered strongly positive, in duration of 10 to $14 \mathrm{~mm}$ was considered weakly positive and in duration $<10 \mathrm{~mm}$ was considered negative for the study.

IGRA test was carried out using commercially available kit (QuantiFERON®TB Gold In-Tube test (Cellestis, Australia)) and manufacturer's instructions were followed. QuantiFERON®-TB Gold IT Analysis Software was used to analyse raw data and calculate results. As recommended by the manufacturer, a positive QFT was defined as IFN $-\gamma$ greater than or equal to $0.35 \mathrm{IU} / \mathrm{ml}$.

All students underwent AFB smear study, culture analysis for sputum samples and chest radiograph to rule out active tuberculosis.
TST and IGRA tests were repeated after 18 months to look for conversions and reversions.

\section{Statistical analyses}

Sensitivity, specificity, confidence interval were calculated for both TST and IGRA tests using SPSS Version 16 software. MediCalc software was used for diagnostic test evaluation. Association between TST and QFT changes were also evaluated at various thresholds, with TST and QFT treated as continuous measures.

\section{Results and Discussion}

\section{Base line testing}

100 students participated for baseline testing. Among the 100 participants, 83 (83\%) were nursing students and $17(17 \%)$ were medical students. There were $84(84 \%)$ female and 16 (16\%) male participants. Baseline testing was done for all the 100 participants by TST and QFT. 27 (27\%) students were positive by either TST or QFT; when TST cut-off was $\geq$ $10 \mathrm{~mm}$ and IGRA cut-off was $\geq 0.35 \mathrm{IU} / \mathrm{ml}$. $26(26 \%)$ of the total 100 students had a TST of $\geq 10 \mathrm{~mm}$ and $16(16 \%)$ had a TST of $\geq$ $15 \mathrm{~mm} .8(8 \%)$ had IGRA $\geq 0.35 \mathrm{IU} / \mathrm{ml}$ and 7 $(7 \%)$ had IGRA $\geq 0.70 \mathrm{IU} / \mathrm{ml}$.

At baseline, when less stringent thresholds were used i.e., $\mathrm{TST} \geq 10 \mathrm{~mm}$ and IGRA $\geq 0.35$ IU/ml, 7 (7\%) students were concordant positive by both TST and IGRA. 73 (73\%) students were concordant negative by both the tests. $20(20 \%)$ out of 100 participants were discordant; 19 were TST positive and IGRA negative and 1 student was TST negative and IGRA positive (Table 1).

When the TST and IGRA thresholds were increased to $\geq 15 \mathrm{~mm}$ and $\geq 0.70 \mathrm{IU} / \mathrm{ml}$ respectively, $5(5 \%)$ students were concordant 
positive and $83(83 \%)$ students were concordant negative by both TST and IGRA. $12(12 \%)$ students were discordant; 10 were TST positive and IGRA negative and 2 students were TST negative and IGRA positive (Table 2).

Results were also evaluated for threshold of $\mathrm{TST} \geq 15 \mathrm{~mm}$ and IGRA $\geq 0.35 \mathrm{IU} / \mathrm{ml}$. It was found that 6 students $(6 \%)$ were concordant positive and $83(83 \%)$ were concordant negative. $11(11 \%)$ had discordant results of which $2(2 \%)$ were TST negative and IGRA positive and $9(9 \%)$ were TST positive and IGRA negative (Table 3 ).

The concordance between TST and IGRA was high $(\mathrm{k}=0.585)$ at low threshold when compared to concordance at high threshold ( $\mathrm{k}$ $=0.052$ ). It was observed that when less stringent thresholds were used for both the tests, there was greater discordance between TST and IGRA.

During baseline testing, when less stringent thresholds were used for both TST and QFT, the sensitivity was $87.50 \%(95 \% \mathrm{CI}=47.38-$ $97.93 \%)$ and specificity was $79.35 \%(95 \%$ CI $=69.64-87.08 \%)$. When stringent thresholds were used for both TST and QFT, the sensitivity was $71.43 \%(95 \% \mathrm{CI}=29.27$ $95.48 \%)$ and specificity was $88.17 \%$ (95\% CI $=79.82-93.94 \%)$. It was also found that with $\mathrm{TST} \geq 15 \mathrm{~mm}$ and IGRA $\geq 0.35 \mathrm{IU} / \mathrm{ml}$, the sensitivity was $37 \%(95 \% \mathrm{CI}=15.29-$ $64.23 \%)$ and specificity was $97 \%(95 \% \mathrm{CI}=$ $91.64-99.64 \%$ ) (Table 4).

\section{Serial testing}

Serial testing was carried out in 40 nursing students after 18 months by both TST and IGRA to look for conversions and reversions. Out of the 40 students, $37(92.5 \%)$ were female students and $3(7.5 \%)$ were male students.
TST conversion was defined as baseline TST $<10 \mathrm{~mm}$ and follow-up TST $\geq 10 \mathrm{~mm}$. QFT conversion was defined as baseline IGRA $\leq$ $0.35 \mathrm{IU} / \mathrm{ml}$ and follow-up IGRA $\geq 0.35$ IU/ml. TST reversion was defined as baseline TST $\geq 10 \mathrm{~mm}$ and follow-up TST $<10 \mathrm{~mm}$. QFT reversion was defined as baseline IGRA of $\geq 0.35 \mathrm{IU} / \mathrm{ml}$ and follow-up IGRA of $\leq$ $0.35 \mathrm{IU} / \mathrm{ml}$.

Conversion and reversion were also analyzed by increasing the TST and IGRA threshold. TST conversion was defined as baseline TST $<15 \mathrm{~mm}$ and follow-up TST $\geq 15 \mathrm{~mm}$; and baseline IGRA $\leq 0.70 \mathrm{IU} / \mathrm{ml}$ and follow-up IGRA $\geq 0.70 \mathrm{IU} / \mathrm{ml}$. TST reversion was defined as baseline TST $\geq 15 \mathrm{~mm}$ and followup TST $<15 \mathrm{~mm}$. QFT reversion was defined as baseline IGRA of $\geq 0.70 \mathrm{IU} / \mathrm{ml}$ and follow-up IGRA of $\leq 0.70 \mathrm{IU} / \mathrm{ml}$.

Out of the 40 nursing students who participated for serial testing, $9(22.5 \%)$ had a TST of $\geq 10 \mathrm{~mm}$ and $7(17.5 \%)$ had a TST of $\geq 15 \mathrm{~mm} .4(20 \%)$ had IGRA $\geq 0.35 \mathrm{IU} / \mathrm{ml}$ and $3(7.5 \%)$ had IGRA $\geq 0.70 \mathrm{IU} / \mathrm{ml}$.

At serial testing, when less stringent thresholds were used i.e., TST $\geq 10 \mathrm{~mm}$ and IGRA $\geq 0.35 \mathrm{IU} / \mathrm{ml}, 4(10 \%)$ students were concordant positive by both TST and IGRA. $31(77.5 \%)$ students were concordant negative by both the tests. $5(12.5 \%)$ out of 40 participants were discordant; 5 were TST positive and IGRA negative (Table 5).

When the TST and IGRA thresholds were increased to $\geq 15 \mathrm{~mm}$ and $\geq 0.70 \mathrm{IU} / \mathrm{ml}$ respectively, $3(7.5 \%)$ students were concordant positive and $33(82.5 \%)$ students were concordant negative by both TST and IGRA. 4 (10\%) students were discordant; 4 were TST positive and IGRA negative (Table 6). With stringent thresholds it was observed that there was reduced discordance (10\%) between TST and IGRA when compared to 
discordance with lesser stringent thresholds $(12.5 \%)$.

With less stringent thresholds, 2 (5\%) students were noticed to have conversions. 1 $(2.5 \%)$ had TST conversion and $1(2.5 \%)$ had QFT conversion. 10 (25\%) students had reversions. $8(20 \%)$ students had TST reversion and $2(5 \%)$ had QFT reversion.

When the thresholds for TST and IGRA were raised, $4(10 \%)$ students had conversions. 3 (7.5\%) students had TST conversions and 1 $(2.5 \%)$ had QFT conversion. 8 (20\%) had reversions. $6(15 \%)$ students had TST reversion and $2(5 \%)$ had QFT reversion.

During serial testing in 40 participants, when less stringent thresholds were used for both TST and QFT, the sensitivity was $100 \%$ $(95 \% \mathrm{CI}=40.23-100 \%)$ and specificity was $86.11 \%$ (95\% CI $=70.49-95.28 \%)$. When stringent thresholds were used for both TST and QFT, the sensitivity was $100 \%(95 \% \mathrm{CI}=$ $30.24-100 \%$ ) and specificity was $89.19 \%$ $(95 \% \mathrm{CI}=74.56-96.91 \%)$. With $\mathrm{TST} \geq$ $15 \mathrm{~mm}$ and IGRA $\geq 0.35 \mathrm{IU} / \mathrm{ml}$, the sensitivity was $100 \%(95 \% \mathrm{CI}=40.23-100 \%)$ and specificity was $91.67 \%(95 \% \mathrm{CI}=77.51-$ 98.15\%) (Table 7).

During baseline testing, sensitivity was higher $(87.5 \%)$ when less stringent thresholds were used for both TST and IGRA (i.e., TST $\geq$ $10 \mathrm{~mm}$ and IGRA $\geq 0.35 \mathrm{IU} / \mathrm{ml}$ ); and specificity was higher $(97 \%)$ with TST cutoff $\geq 15 \mathrm{~mm}$ and IGRA cut-off $\geq 0.35 \mathrm{IU} / \mathrm{ml}$. With TST threshold $\geq 15 \mathrm{~mm}$ and IGRA threshold $\geq 0.70 \mathrm{IU} / \mathrm{ml}$ sensitivity was 71.43 $\%$ and specificity was $88.17 \%$; and agreement was higher with higher thresholds.

The use of less stringent thresholds for TST or QFT could potentially result in misclassification of nonspecific variations as new infections. Therefore, a TST value of $\geq$
$15 \mathrm{~mm}$ and IGRA value of $\geq 0.70 \mathrm{IU} / \mathrm{ml} \mathrm{might}$ be more specific for detecting new infections.

During serial testing, sensitivity was $100 \%$ with both less stringent and stringent thresholds; specificity was higher $(91.67 \%)$ with TST cut-off $\geq 15 \mathrm{~mm}$ and IGRA cut-off $\geq$ $0.35 \mathrm{IU} / \mathrm{ml}$. So, TST threshold of $\geq 15 \mathrm{~mm}$ and IGRA threshold $\geq 0.35 \mathrm{IU} / \mathrm{ml}$ might be more specific for detecting conversions and reversions.

Over all, the results showed that conversions, reversions and nonspecific variations occur with serial IGRA testing, as they do with TST. TST and QFT results are threshold dependent.

An estimated $40 \%$ of the Indian population is infected and the annual risk of infection is 1.5\% (Devasahayam et al., 2010; Chadha, 2003). The risk of transmission of MTB between patients and HCWs is well recognized. HCWs in India are constantly exposed to infectious TB patients (Devasahayam et al., 2010).

With the emergence of MDR-TB and XDRTB there has been a renewed interest in TB infection control, especially in resource limited settings with high $\mathrm{TB}$ and HIV prevalence (Basu et al., 2007; 2009). Nosocomial transmission appears to play an important role in amplifying XDR - TB transmission (Veriko et al., 2008).

Several studies have shown a positive association between TST response and subsequent risk of active TB, and randomizes trials have shown that treatment of LTBI, diagnosed using TST, reduces the risk of active TB by $60 \%$ to $90 \%$ (American Thoracic Society, 2000). The TST has limitations with respect to accuracy and reliability (Huebner et al., 1993). Advances in genomics and immunology have led to a 
promising alternative, the in vitro IFN- $\gamma$ assay (Pai et al., 2004; Andersen et al., 2000; Lalvani, 2003), based on the concept that Tcells of infected individuals release IFN- $\gamma$.

Recent data from India suggests that nearly $40 \%$ of HCWs may have LTBI, as measured by positivity in either TST or IGRA, and increasing age and years in the health profession were significant risk factors for positivity. The ARTI among medical and nursing trainees has been estimated to be approximately 5\% (Pai et al., 2006), which is substantially higher than the ARTI in the general population which is estimated at $1.5 \%$ (Chadha et al., 2005).

In this study, during baseline testing, 27\% were positive either by TST or IGRA. When the TST and IGRA thresholds were kept low, 26\% were TST positive and $8 \%$ were QFT positive; $7 \%$ were concordant positive and 73\% were concordant negative. 20\% were discordant i.e., 19 were TST positive and IGRA negative and 1 student was TST negative and IGRA positive. When thresholds were stringent, $16 \%$ were TST positive and $7 \%$ were QFT positive.

The prevalence of LTBI was found to range from $16-26 \%$ among the nursing and medical students using TST; and $7-8 \%$ using QFT. The prevalence of approximately $26 \%$ may an underestimate because of the small sample size.

With stringent thresholds, $5(5 \%)$ students were concordant positive and $83 \%$ students were concordant negative. $12 \%$ were discordant i.e., 10 were TST positive and IGRA negative and 2 students were TST negative and IGRA positive. The concordance between TST and IGRA was high $(\mathrm{k}=0.585)$ at low threshold when compared to concordance at high threshold $(\mathrm{k}=0.052)$. Although TST and IGRA use different antigen combination, it was noticed that these tests had high level of agreement at low threshold values. This was comparable to the study conducted by Pai et al., (2006) in $\mathrm{HCW}$ in rural India.

During baseline testing, when less stringent thresholds were used for both TST and QFT, the sensitivity was $87.50 \%$ (95\% CI $=47.38$ $97.93 \%)$ and specificity was $79.35 \%(95 \%$ CI $=69.64-87.08 \%$ ). When stringent thresholds were used for both tests, the sensitivity was $71.43 \%$ (95\% CI $=29.27$ $95.48 \%)$ and specificity was $88.17 \%$ (95\% CI $=79.82-93.94 \%)$. It was also found that with TST $\geq 15 \mathrm{~mm}$ and IGRA $\geq 0.35 \mathrm{IU} / \mathrm{ml}$, the sensitivity was $37 \%(95 \% \mathrm{CI}=15.29-$ $64.23 \%)$ and specificity was $97 \%(95 \% \mathrm{CI}=$ $91.64-99.64 \%$ ). This showed that during baseline testing stringent thresholds should be used for detection of LTBI because the use of less stringent thresholds could potentially result in false-positives.

Serial testing was done 18 months after the base-line testing to look for conversions and reversions. 40 nursing students, who had initially undergone baseline testing, participated for the serial testing. With less stringent thresholds, 2 (5\%) students were noticed to have conversions. 1 (2.5\%) had TST conversion and 1 (2.5\%) had QFT conversion. 10 (25\%) students had reversions. $8(20 \%)$ students had TST reversion and 2 (5\%) had QFT reversion. When the thresholds for TST and IGRA were raised, 4 (10\%) students had conversions. 3 (7.5\%) students had TST conversions and 1 (2.5\%) had QFT conversion. $8(20 \%)$ students had reversions. $6(15 \%)$ students had TST reversion and 2 (5\%) had QFT reversion.

It was noticed that some students who were positive by either TST/IGRA during the baseline testing reverted to negative during serial testing without any treatment, suggesting transient, non-progressive LTBI. 
Table.1 Results obtained at low threshold value during baseline testing

\begin{tabular}{|l|c|c|c|}
\hline TST and IGRA Threshold Values & $\begin{array}{c}\text { Nursing } \\
\text { Students } \\
(\mathbf{N = 8 3 )}\end{array}$ & $\begin{array}{c}\text { Medical } \\
\text { Students } \\
(\mathbf{N = 1 7})\end{array}$ & $\begin{array}{c}\text { Total } \\
(\mathbf{N}=\mathbf{1 0 0})\end{array}$ \\
\hline TST $\geq 10 \mathrm{~mm}$ and IGRA $\geq 0.35 \mathrm{IU} / \mathrm{ml}$ & 05 & 02 & $07(7 \%)$ \\
\hline TST $<10 \mathrm{~mm}$ and IGRA $\geq 0.35 \mathrm{IU} / \mathrm{ml}$ & 01 & 0 & $01(1 \%)$ \\
\hline TST $\geq 10 \mathrm{~mm}$ and IGRA $<0.35 \mathrm{IU} / \mathrm{ml}$ & 16 & 03 & $19(19 \%)$ \\
\hline TST $<10 \mathrm{~mm}$ and IGRA $<0.35 \mathrm{IU} / \mathrm{ml}$ & 61 & 12 & $73(73 \%)$ \\
\hline
\end{tabular}

Table.2 Results obtained at stringent threshold values during baseline testing

\begin{tabular}{|l|c|c|c|}
\hline \multicolumn{1}{|c|}{ TST and IGRA Threshold Values } & $\begin{array}{c}\text { Nursing } \\
\text { Students } \\
(\mathbf{N}=\mathbf{8 3})\end{array}$ & $\begin{array}{c}\text { Medical } \\
\text { Students } \\
(\mathbf{N}=\mathbf{1 7})\end{array}$ & $\begin{array}{c}\text { Total } \\
(\mathbf{N}=\mathbf{1 0 0})\end{array}$ \\
\hline $\mathrm{TST} \geq 15 \mathrm{~mm}$ and IGRA $\geq 0.70 \mathrm{IU} / \mathrm{ml}$ & 04 & 01 & $05(5 \%)$ \\
\hline $\mathrm{TST}<15 \mathrm{~mm}$ and IGRA $\geq 0.70 \mathrm{IU} / \mathrm{ml}$ & 01 & 01 & $02(2 \%)$ \\
\hline $\mathrm{TST} \geq 15 \mathrm{~mm}$ and IGRA $<0.70 \mathrm{IU} / \mathrm{ml}$ & 10 & 0 & $10(10 \%)$ \\
\hline TST $<15 \mathrm{~mm}$ and IGRA $<0.70 \mathrm{IU} / \mathrm{ml}$ & 68 & 15 & $83(83 \%)$ \\
\hline
\end{tabular}

Table.3 Results obtained at threshold of $15 \mathrm{~mm}$ for TST and $0.35 \mathrm{IU} / \mathrm{Ml}$ for IGRA

\begin{tabular}{|l|c|c|c|}
\hline TST and IGRA Threshold Values & $\begin{array}{c}\text { Nursing } \\
\text { Students } \\
(\mathbf{N = 8 3 )}\end{array}$ & $\begin{array}{c}\text { Medical } \\
\text { Students } \\
(\mathbf{N = 1 7})\end{array}$ & $\begin{array}{c}\text { Total } \\
\mathbf{N}=\mathbf{1 0 0})\end{array}$ \\
\hline TST $\geq 15 \mathrm{~mm}$ and IGRA $\geq 0.35 \mathrm{IU} / \mathrm{ml}$ & 05 & 01 & $06(6 \%)$ \\
\hline TST $<15 \mathrm{~mm}$ and IGRA $\geq 0.35 \mathrm{IU} / \mathrm{ml}$ & 01 & 01 & $02(6 \%)$ \\
\hline TST $\geq 15 \mathrm{~mm}$ and IGRA $<0.35 \mathrm{IU} / \mathrm{ml}$ & 09 & 0 & $09(9 \%)$ \\
\hline TST $<15 \mathrm{~mm}$ and IGRA $<0.35 \mathrm{IU} / \mathrm{ml}$ & 68 & 15 & $83(83 \%)$ \\
\hline
\end{tabular}

Table.4 Sensitivity, specificity and 95\% CI for various threshold value during baseline testing

\begin{tabular}{|c|c|c|}
\hline Threshold Value & Sensitivity and Specificity & 95\% CI \\
& & \\
\hline TST $\geq 10 \mathrm{~mm}$ and IGRA $\geq 0.35 \mathrm{IU} / \mathrm{ml}$ & Sensitivity $=87.5 \%$ & $47.38-97.93 \%$ \\
& Specificity $=79.35 \%$ & $47.38-97.93 \%$ \\
\hline $\mathrm{TST} \geq 15 \mathrm{~mm}$ and IGRA $\geq 0.35 \mathrm{IU} / \mathrm{ml}$ & Sensitivity $=37 \%$ & $15.29-64.23 \%$ \\
& Specificity $=97 \%$ & $91.64-99.64 \%$ \\
\hline $\mathrm{TST} \geq 15 \mathrm{~mm}$ and IGRA $\geq 0.70 \mathrm{IU} / \mathrm{ml}$ & Sensitivity $=71.43 \%$ & $29.27-95.48 \%$ \\
& Specificity $=88.17 \%$ & $79.82-93.94 \%$ \\
\hline
\end{tabular}


Table.5 Results obtained at low threshold values during serial testing

\begin{tabular}{|c|c|}
\hline TST and IGRA Threshold Values & $\begin{array}{c}\text { Nursing Students } \\
(\mathbf{N}=\mathbf{4 0})\end{array}$ \\
\hline $\mathrm{TST} \geq 10 \mathrm{~mm}$ and IGRA $\geq 0.35 \mathrm{IU} / \mathrm{ml}$ & $04(10 \%)$ \\
\hline $\mathrm{TST}<10 \mathrm{~mm}$ and $\mathrm{IGRA} \geq 0.35 \mathrm{IU} / \mathrm{ml}$ & $0(0 \%)$ \\
\hline $\mathrm{TST} \geq 10 \mathrm{~mm}$ and $\mathrm{IGRA}<0.35 \mathrm{IU} / \mathrm{ml}$ & $05(12.5 \%)$ \\
\hline $\mathrm{TST}<10 \mathrm{~mm}$ and $\mathrm{IGRA}<0.35 \mathrm{IU} / \mathrm{ml}$ & $31(77.5 \%)$ \\
\hline
\end{tabular}

Table.6 Results obtained at stringent threshold values during serial testing

\begin{tabular}{|l|c|}
\hline TST and IGRA Threshold Values & $\begin{array}{c}\text { Nursing Students } \\
(\mathbf{N}=\mathbf{4 0})\end{array}$ \\
\hline TST $\geq 15 \mathrm{~mm}$ and IGRA $\geq 0.70 \mathrm{IU} / \mathrm{ml}$ & $03(7.5 \%)$ \\
\hline TST $<15 \mathrm{~mm}$ and IGRA $\geq 0.70 \mathrm{IU} / \mathrm{ml}$ & $0(0 \%)$ \\
\hline TST $\geq 15 \mathrm{~mm}$ and IGRA $<0.70 \mathrm{IU} / \mathrm{ml}$ & $04(10 \%)$ \\
\hline TST $<15 \mathrm{~mm}$ and IGRA $<0.70 \mathrm{IU} / \mathrm{ml}$ & $33(82.5 \%)$ \\
\hline
\end{tabular}

Table.7 Sensitivity, specificity and $95 \%$ CI for various threshold value during serial testing

\begin{tabular}{|c|c|c|}
\hline Threshold Value & $\begin{array}{c}\text { Sensitivity and } \\
\text { Specificity }\end{array}$ & 95\% CI \\
& Sensitivity $=100 \%$ & $40.23-100 \%$ \\
TST $\geq 10 \mathrm{~mm}$ and IGRA $\geq 0.35 \mathrm{IU} / \mathrm{ml}$ & Specificity $=86.11 \%$ & $70.49-95.28 \%$ \\
\hline $\mathrm{TST} \geq 15 \mathrm{~mm}$ and IGRA $\geq 0.35 \mathrm{IU} / \mathrm{ml}$ & Sensitivity $=100 \%$ & $40.23-100 \%$ \\
& Specificity $=91.67 \%$ & $77.51-98.15 \%$ \\
\hline $\mathrm{TST} \geq 15 \mathrm{~mm}$ and IGRA $\geq 0.70 \mathrm{IU} / \mathrm{ml}$ & Sensitivity $=100 \%$ & $30.24-100 \%$ \\
& Specificity $=89.19 \%$ & $74.56-96.91 \%$ \\
\hline
\end{tabular}

With low threshold values, $25 \%$ students had reversions. $20 \%$ had TST reversion and $5 \%$ had QFT reversion. With stringent threshold values, $20 \%$ had reversion. $15 \%$ students had TST reversion and 5\% had QFT reversion. Pai et al., (2006) reported QFT reversion of $55 \%$ with low threshold value and $50 \%$ with high threshold value.

During serial testing, when less stringent thresholds were used for both TST and QFT, the sensitivity was $100 \%(95 \% \mathrm{CI}=40.23-$ $100 \%$ ) and specificity was $86.11 \%$. With stringent thresholds, the sensitivity was $100 \%$ and specificity was $89.19 \%$. Sensitivity and specificity were also calculated for cut-off values of TST $\geq 15 \mathrm{~mm}$ and IGRA $\geq 0.35$ $\mathrm{IU} / \mathrm{ml}$, and the sensitivity was $100 \%$ and specificity was $91.67 \%$. This showed that during serial testing, for detection of conversions and reversions, threshold of TST $\geq 15 \mathrm{~mm}$ and IGRA $\geq 0.35 \mathrm{IU} / \mathrm{ml}$ had greater sensitivity and specificity.

Screening of HCWs for TB is an important component of infection control programs (Menzies et al., 1995; Blumberg, 2004; Centers for Disease Control and Prevention, 2005; World Health Organization, 1999). Routine TST and IGRA of HCWs with patient contact should be part of the screening program and should be conducted on an 
annual basis, with a major effort to institute treatment for LTBI. IGRAs are more specific than TST, and have characteristics suited for serial testing (Pai et al., 2006). To fully evaluate the use of IFN- $\gamma$ assays, long-term cohort studies to determine the association between positive IFN- $\gamma$ assay results and the subsequent risk of active tuberculosis are required in diverse settings (Pai et al., 2004). If such studies demonstrate a strong consistent association, IFN- $\gamma$ assay might have the potential to replace TST.

There is a greater need of improved infection control programme and providing necessary treatment facilities and support to the HCWs who are the occupational risk group. Combination of TST and IFN- $\gamma$ assay serially done with a gap of 12 to 18 months is more reliable than a single test. An intensive and committed campaign globally against $\mathrm{TB}$ is the only solution to reach the WHO goal of 1 TB patient per 100,000 population by the year 2050. Research and development in the form of providing the latest diagnostic equipments to medical colleges helps in maintaining a national data with regard to TBI and LTBI in HCWs.

\section{Acknowledgement}

This work was supported by nursing and medical students. I offer my sincere thanks to all the students who participated in the study.

\section{References}

American Thoracic Society. 2000. Targeted tuberculin testing and treatment of latent tuberculosis infection. Am. J. Respir. Crit. Care Med., 161: S 221- S 247.

Andersen, P., Munk, M.E., Pollock, J.M., Doherty, T.M. 2000. Specific immune- based diagnosis of tuberculosis. Lancet, 356: 1099 - 1104.

Basu, S., Andrews, J.R., Poolman, E.M., Gandhi, N.R., Shah, N.S., et al. 2007. Prevention of nosocomial transmission of extensively drug-resistant tuberculosis in rural South African district hospitals: an epidemiological modelling study. Lancet, 370: 15001507.

Basu, S., Friedland, G.H., Medlock, J., Andrews, J.R., Shah, N.S., et al. 2009. Averting epidemics of extensively drugresistant tuberculosis. Proc. Natl. Acad. Sci. U S A., 106: 7672-7677.

Blumberg, H. 2004. M. tuberculosis infection control in health care settings. In: Lautenbach E, Woeltje K. Practical handbook for health- care epidemiologists. Thorofare, NJ: Slack Incorporated, 259-273.

Centers for Disease Control and Prevention. Guidelines for preventing the transmission of Mycobacterium tuberculosis in health-care settings, 2005. $M M W R, 54:$ 1-141.

Chadha, V.K. 2003. Epidemiological situation of tuberculosis in India. J. Indian Med. Assoc., 101: 144 - 147.

Chadha, V.K., Kumar, P., Jagannatha, P.S., Vaidyanathan, P.S., Unnikrishnan, K.P. 2005. Average annual risk of tuberculous infection in India. Int. J. Tuberc. Lung Dis., 9: 116-118.

Devasahayam, J., Christopher, Peter Daley, Lois Armstrong, Prince James, Richa Gupta, Beulah Premkumar, et al. 2010. Tuberculosis Infection among Young Nursing Trainees in South India. PLoS One, 5(4): e10408

Huebner, R.E., Schein, M.F., Bass, J.B. Jr. 1993. The tuberculin skin test. Clin. Infect. Dis., 17: 968 - 975.

Joshi, R., Reingold, A.L., Menzies, D., Pai. 2006. M. tuberculosis among healthcare workers in low- and middle- 
income countries: a systematic review. PLoS Med., 3(12): 2376 - 2391.

Khatri, G.R., Frieden, T.R. 2002. Controlling tuberculosis in India. N. Engl. J. Med., 347: $1420-1425$

Lalvani, A. 2003. Spotting latent infection: the path to better tuberculosis control. Thorax, 58: 916 - 918.

Mack, U., Milgori, G.B., Sester, M., Rieder, H.L., et al. 2009. LTBI: latent tuberculosis infection or lasting immune response to $M$. tuberculosis A TBNET consensus statement. Eur. Respir. J., 33(5): 956 - 973 .

Menzies, D., Fanning, A., Yuan, L., Fitzgerald.995. M. tuberculosis among health care workers. N. Engl. J. Med., 332: 92-98.

Pai, M., Riley, L.W., Colford, J.M., Jr. 2004. Interferon- $\gamma$ assays in the immunodiagnosis of tuberculosis: a systematic review. Lancet Infect. Dis., 4: 761776.

Veriko Mirtskhulava, Russell Kempker, Katherine, L., Shields, Michael, K. Leonard, Tengiz Tsertsvadze, Carlos del Rio et al. 2008. Prevalence and Risk Factors for Latent Tuberculosis
Pai, M., Gokhale, K., Joshi, R., Dogra, S., Kalantri, S., et al. 2005. ycobacterium tuberculosis infection in health care workers in rural India: comparison of a whole-blood interferon gamma assay with tuberculin skin testing. JAMA, 93: 2746-2755.

Pai, M., Joshi, R., Dogra, S., Mendiratta, D.K., Narang, P., et al. 2006. Serial testing of health care workers for tuberculosis using interferon- $\gamma$ assay. Am. J. Respir. Crit. Care Med., 174: 349-355.

Pai, M., Kalantri, S., Dheda, K. 2006. New tools and emerging technologies for the diagnosis of tuberculosis: Part 1. Latent tuberculosis. Expert Rev. Mol. Diagn., 6:

413-422.

Infection among Health-care Workers in the Country of Georgia. Int. J. Tuberc. Lung Dis., 12(5): 513-519.

World Health Organization. 1999. Guidelines for the prevention of tuberculosis in health care facilities in resource-limited settings. Geneva: World Health Organization.

\section{How to cite this article:}

Reshmi Gopalakrishnan and Vijay Kumar, G.S. 2017. Interferon Gamma Release Assay and Tuberculin Skin Test in the Diagnosis of Latent Tuberculosis among Health Care Workers - A Comparative Study. Int.J.Curr.Microbiol.App.Sci. 6(6): 2360-2368.

doi: https://doi.org/10.20546/ijcmas.2017.606.280 